\title{
The production of English initial /s/ clusters by Portuguese and Spanish EFL speakers
}

\author{
Andreia Schurt Rauber \\ Universidade Federal de Santa Catarina \\ Barbara Oughton Baptista \\ Universidade Federal de Santa Catarina
}

\section{Resumo}

Este estudo revisa, verifica e explica os diferentes resultados obtidos por Carlisle (1991, 1992, 1997) e Rebello (1997) sobre a produção de encontros consonantais iniciais /sC(C)/ em inglês por falantes de português e espanhol, complementando os resultados obtidos em pesquisas anteriores na área de interfonologia, já que o mesmo corpus foi usado para comparar a produção de falantes das duas línguas nativas. Os resultados revelam que a adição de uma vogal (epêntese) aos encontros consonantais iniciais é a estratégia mais utilizada para se lidar com as dificuldades relativas às estruturas silábicas mais difíceis, o que pode ser resultado da relação entre a interferência da língua materna e os universais lingüísticos. Os resultados fornecem informações relevantes ao ensino da pronúncia do inglês no Brasil e nos demais países sul-americanos. 


\section{INTRODUCTION}

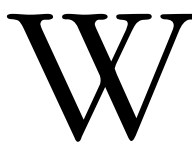

ith the importance of English as an international language, some special attention to pronunciation should be given in English as a foreign language (EFL) classes, since the reconceptualization of the role of English in the world has generated different purposes for learning it. Seidlhofer (2001) discusses the importance of stress and the amount of effort that should be put into the teaching of significantly different sounds between the native language (NL) and the target language (TL) compared to easier sounds that could be less emphasized. In this sense, Seidlhofer (2001) claims that teachers should be aware of "how much work individual sounds, or sound contrasts, actually do in a particular language, that is, whether they have a high or low functional load" (p. 59).

Characterized in this way, the aim of this study is to investigate the difficulty in the production of initial /s/ clusters by Portuguese and Spanish EFL speakers. This difficulty has already been investigated with Spanish speakers by Carlisle (1991, 1992, 1997) and with Portuguese speakers by Rebello (1997). In their studies, the production of epenthesis (the addition of an extra vowel) to the initial clusters was the usual strategy for dealing with syllable structure difficulty, given that in both Portuguese and Spanish, /s/-clusters are invariably preceded by a vowel.

Since Carlisle and Rebello report divergent findings, this investigation aimed at verifying and explaining the different results obtained by the two researchers. Following Carlisle's (1991, 1992, 1997) and Rebello's (1997) studies, three variables were investigated as to their influence on the production of /s/ clusters: the structure of the cluster, its length and the phonological context where it occurs.

This article was divided into five sections. The first section presents a brief review of the literature on the syllable structures of 
English, Portuguese and Spanish, as well as some studies on IL syllable structure based on the Markedness Differential Hypothesis (MDH). The second section describes the hypotheses elaborated for this study and the method adopted to collect and analyze the data. The third section provides the analysis of the results, which are discussed in the following section. The fifth section discusses some pedagogical implications, limitations and suggestions for further research.

\section{SYLLABLE STRUCTURE OF THE LANGUAGES IN QUESTIONS}

Since the aim of this study is to investigate how Brazilian Portuguese and Argentinean Spanish speakers produce English initial /s/ clusters, the main syllable structure features of each language will be briefly described, and some studies that show the main strategies used by learners to avoid this difficulty will be reported.

According to Brinton (2000, p. 65), the onset in English may optionally contain up to three consonants and the coda may be formed by one to four consonants, which can be represented as (C) (C) (C) (V) (C) (C) (C) (C). This wide variety of English syllable types can be considered one of the reasons EFL learners face difficulty in producing them correctly. Consonant clusters constitute an important aspect of restrictions on syllable types, since there is a limited number of allowed combinations of segments in both initial and final positions. Clusters with initial /s/, for instance, are the only instances of onsets where the second consonant may be an obstruent and where the onset may be formed by three consonants instead of one or two.

When considering the possible combinations of segments within the syllable structures of both Portuguese and Spanish, it is possible to observe that there is a rather limited number of clusters. The phoneme /s/, for instance, occurs in syllable-initial position when not followed by any other consonant in the three languages; however, it forms initial clusters only in English. This difference is significantly relevant for the study on the production of initial /s/ clusters by EFL learners, since it accounts partially for the difficulty in producing this structure. 
In order to better understand the findings related to the production of the /s/ clusters, the Markedness Differential Hypothesis (MDH) and the Structural Conformity Hypothesis ( $\mathrm{SCH}$ ), both elaborated by Eckman (1977) and Eckman (1996), were the theories chosen to give support to the investigation. The first theory proposes that language universals and NL transfer predict difficulties in TL learning. This means that TL structures which are different from and more marked than the corresponding NL structures will be difficult to learn and that the relative degree of difficulty "will correspond to the relative degree of markedness". Katamba (1989, p. 98) defines markedness in terms of naturalness: what is natural can be considered unmarked in a language, and what is not natural can be considered marked or in some sense unusual. While the MDH makes predictions on the basis of both universals and differences between the NL and the TL, the second theory, the $\mathrm{SCH}$, makes predictions only on the basis of universals, that is, it considers the tendency interlanguages (learners' transitory competence or intermediary system between NL and TL) have to follow the same universal principles that primary languages do.

There are several studies that show the main strategies used by learners to avoid syllable structure difficulty. Some of them, as previously stated, were highly relevant and were considered the starting point for this study. Carlisle carried out several studies involving native Spanish-speaking learners of English as a second language, who were asked to read a number of topically unrelated and randomly ordered sentences containing initial /s/-clusters in two types of environment. Carlisle (1991) examined epenthesis before three word-initial onsets in English: /sp/, /st/ and /sk/; Carlisle (1992) investigated the production of epenthesis before the word-initial onsets /sl/, /sm/ and /sn/; and Carlisle (1997) compared the production of $/ \mathrm{sC} / \mathrm{vs}$. $/ \mathrm{sCC} /$ clusters. All the studies controlled the environments before the onsets and the sonority relationships among the consonants in the onsets. His findings in the three studies revealed that vowel epenthesis was significantly more frequent after consonants than after vowels. Concerning the variable length 
examined in Carlisle (1997), his findings reveal that tri-literal clusters, whose structure is more marked, were more frequently modified than bi-literal clusters, confirming that language universals "influence the structuring of interlanguage phonology" (p. 327).

In another study, Rebello (1997) adopted a type of instrumentation similar to that of Carlisle, but investigated Portuguese-speaking learners of English. She included six English two-segment /s/ clusters (/sp, st, sk, sm, sn, sl/), and five three-segment /s/ clusters (/spr, str, skr, spl, skw/) and found results contrary to those of Carlisle (1991, 1992, 1997). Concerning the phonological environment, epenthesis occurred most frequently after silence, followed by vowels and finally by consonants. Although there was little difference in the results concerning the variable length, Rebello's (1997) findings are contrary to those of Carlisle (1997), since epenthesis was more frequently produced before bi-literal clusters than tri-literal clusters, the latter being more marked. As to the structure of the word-initial onsets, Rebello found that bi-literal clusters not in violation of Hooper's (1976) sonority hierarchy principle were more frequently modified than bi-literal clusters in violation and than tri-literal clusters, which are all in violation. Her results contradict expectations based on Hooper (1976, p. 206) that clusters in violation should be more frequently modified than clusters not in violation. Rebello's (1997) explanation for these unexpected findings regarding length and structure of the cluster is that participants tended to voice the /s/ before /s/-nasal and /s/-liquid clusters (transfer of the voicing assimilation process in Portuguese), which resulted in voiced obstruent + sonorant clusters. Since voiced obstruents are more marked than voiceless obstruents in any position, these clusters can be considered to be more marked than voiceless obstruent + obstruent clusters. Thus, she considers her results to conform to the $\mathrm{MDH}$ and the SCH, since "the more marked type of cluster caused more epenthesis than the less marked type". This difference in results deserved much attention in the present study in order to confirm whether the NL does have such an influence on TL production as to result in opposite findings. 


\section{METHOD}

Participants: nine native Spanish speakers from Argentina, enrolled in the introductory, first and second years of the Letras course at the University of Montoya, in the city of Posadas, in the province of Misiones; and ten native Portuguese speakers from Brazil, enrolled in the second and third years of the Letras course at the Universidade Federal de Santa Catarina (UFSC), in the city of Florianópolis.

Material: participants were asked to read 180 topically-unrelated sentences, an instrumentation similar to that in both Carlisle's and Rebello's studies. This technique was preferred to guarantee all relevant phonological contexts were present in the corpus. The corpus included 13 sentences containing one occurrence of each of the bi-literal and tri-literal/s/ clusters: /sp, st, sk, sw, sm, sn, sl, spr, str, skr, spl, skw/, each preceded by 5 vowels, 5 consonants, and 3 null contexts (silence). This gave a total of 156 target sentences, to which were added 24 distractor sentences, meaning each participant read 180 sentences. Each subject read the sentences in a different order to prevent any possible ordering effect. Some of the sentences used in this study were taken with permission from Rebello's (1997) corpus.

Transcription: only the part of each sentence considered relevant to this study was transcribed. Three aspects were focused on: The absence or presence of the epenthetic vowel, the phonetic realization of the preceding environments, and the phonetic representation of the onsets. The relevant sections of each sentence were first transcribed by the researcher twice, within the interval of a week. Then the items were independently transcribed by one more judge with experience in phonetic transcription. Consequently, out of the 2,964 items read, 2,808 (94.74\%) were left for statistical analysis.

Statistical analysis: the chi-square (X2) was used to analyze the variables considered to be possible constraints in the production of accurate segments. This procedure allows the testing of significance concerning the association of qualitative variables (BARBETTA, 2001). According to Woods, Fletcher and Hughes (1986, p. 144), in order for the chi-square to have satisfactory properties, "all expected 
frequencies must be sufficiently large", and this was the case in this study, since there were a great number of items.

Hypotheses: based on the studies by Carlisle and Rebello, the following hypotheses were formulated concerning, length, structure and phonological context where epenthesis most frequently occurs: (1) Spanish speakers would tend to modify longer clusters, while Portuguese speakers would modify shorter clusters more frequently; (2) Spanish speakers would tend to modify more marked structures, while Portuguese speakers would modify less marked structures more frequently; (3) Spanish speakers would tend to produce more epenthesis after consonants, followed by vowels, and then by silence, while Portuguese speakers would epenthesize the sibilant more frequently after silence, followed by consonants and then by vowels.

\section{RESULTS}

\subsection{General analysis of $/ \mathrm{sC} / \mathrm{vs} . / \mathrm{sCC} /$}

The results of the first analysis are shown in Table 1 and reveal that both Brazilian and Argentinean participants produced significantly more epenthesis before longer clusters, since there was a $9.62 \%$ average difference between / $\mathrm{sC} /$ and /sCC/ clusters within the Brazilian group $(\mathrm{X} 2(1, \mathrm{~N}=1,493)=15.19, \mathrm{p}<.0001)$, and a $10.72 \%$ difference within the group of Argentineans $(\mathrm{X} 2(1, \mathrm{~N}=1,315)=$ 17.98, $\mathrm{p}<.0001$ ).

Table 1 - Total rates of epenthesis production for /sC/ and /sCC/ clusters by Portuguese and Spanish speakers

\begin{tabular}{lcccccc}
\hline \hline & \multicolumn{3}{c}{$/ \mathrm{sC} /$} & & \multicolumn{2}{c}{$/ \mathrm{sCC} /$} \\
Participants \# productions & \# epenthesis & \% epenthesis & \# productions & \# epenthesis & \% epenthesis \\
\hline BR & 866 & 251 & 28.98 & 627 & 242 & 38.60 \\
AR & 774 & 186 & 24.03 & 541 & 188 & 34.75 \\
\hline \hline
\end{tabular}




\subsubsection{Analysis of clusters grouped by second component}

In order to analyze the length of clusters without the intervening variable sonority, the bi-literal and tri-literal clusters were compared grouped by their second component, as shown in Table 2.

Table 2 - Total rates of epenthesis production for clusters grouped by their second component

\begin{tabular}{|c|c|c|c|c|c|c|c|c|c|c|c|c|}
\hline & \multicolumn{3}{|c|}{$/ \mathrm{sp} /$} & \multicolumn{3}{|c|}{ /spr/ } & \multicolumn{3}{|c|}{ /spC/ } & \multicolumn{3}{|c|}{ Both /spC/ } \\
\hline & Prod & Epen & Rate & Prod & Epen & Rate & Prod & Epen & Rate & Prod & Epen & Rate \\
\hline $\mathrm{BR}$ & 125 & 33 & 26.40 & 125 & 45 & 36.0 & 123 & 49 & 39.84 & 248 & 94 & 37.90 \\
\hline \multirow[t]{2}{*}{ AR } & 114 & 30 & 26.32 & 112 & 36 & 32.14 & 99 & 27 & 27.27 & 211 & 63 & 30.81 \\
\hline & & /st/ & & & /str/ & & & & & & & \\
\hline $\mathrm{BR}$ & 129 & 47 & 36.43 & 129 & 50 & 38.76 & & & & & & \\
\hline \multirow[t]{2}{*}{ AR } & 110 & 41 & 37.27 & 113 & 49 & 43.36 & & & & & & \\
\hline & & /sk/ & & & /skr/ & & & /skw/ & & & th $/$ sk & \\
\hline $\mathrm{BR}$ & 115 & 34 & 29.57 & 126 & 47 & 37.30 & 124 & 51 & 41.13 & 250 & 98 & 39.20 \\
\hline Groul & р 109 & 29 & 26.61 & 108 & 32 & 29.63 & 110 & 45 & 40.91 & 218 & 77 & 35.32 \\
\hline
\end{tabular}

As can be observed, although the tendency in the analysis of clusters grouped by second component was to conform to the $\mathrm{MDH}$, since the more marked clusters were more frequently modified, the results are inconclusive, given that difference in epenthesis production between the total rates were not statistically significant, with the only exception being the analysis of /sp/ versus / $\mathrm{spC}$ / clusters produced by Portuguese speakers, which resulted in a significant chi-square $(\mathrm{X} 2(1, \mathrm{~N}=373)=4.39, \mathrm{p}<.04)$ and confirmed that longer clusters are more difficult to produce, since they resulted in a greater rate of epenthesis.

\subsection{Analysis of bi-literal clusters in violation of the Syllable Structure Condition (SSC) vs. bi-literal clusters not in violation}

Another analysis was carried out in order to investigate whether strength relations within the clusters exerted some influence on the 
production of epenthesis. In this analysis, bi-literal /s/ clusters in violation of the sonority hierarchy principle within the syllable $(/ \mathrm{sp} /$, /st/, and /sk/) elaborated by Hooper (1976) were compared to biliteral $/ \mathrm{s} /$ clusters not in violation $(/ \mathrm{sw} /, / \mathrm{sm} /, / \mathrm{sn} /, / \mathrm{sl} /)$, thus eliminating the intervening variable length. In Rebello (1997), the findings did not support the hypothesis based on the SSC, because her participants produced more epenthesis before bi-literal clusters not in violation than bi-literal clusters in violation.

However, the results obtained in this study seem to contradict Rebello's (1997) findings, corroborating theSSC. The figures described in Table 3 show the total frequencies of epenthesis produced by Brazilian and Argentinean participants in the analysis of the structure of the clusters. The total rate of epenthesis produced by these groups revealed that a vowel was more frequently inserted before bi-literal clusters in violation than before bi-literal clusters not in violation, although the figures resulted in a non-significant chi-square for Brazilians (X2 (1, N = 866) = 1.31, p > .25), and a highly significant chi-square for Argentineans $(\mathrm{X} 2(2, \mathrm{~N}=774)=12.25, \mathrm{p}<.0005)$.

Table 3 - Total rates of epenthesis production for clusters not in violation of the SSC vs. clusters in violation

\begin{tabular}{lcccccc}
\hline \hline & \multicolumn{3}{c}{ Bi-literal clusters not in violation } & \multicolumn{3}{c}{ Bi-literal clusters in violation } \\
Participants \# productions & \# epenthesis & \% epenthesis & \# productions & \# epenthesis & \% epenthesis \\
\hline BR & 497 & 137 & $\mathbf{2 7 . 5 7}$ & 369 & 144 & $\mathbf{3 0 . 8 9}$ \\
AR & 441 & 86 & $\mathbf{1 9 . 5 0}$ & 333 & 100 & $\mathbf{3 0 . 0 3}$ \\
\hline \hline
\end{tabular}

\subsubsection{Voicing assimilation of /s/-sonorant clusters by Portuguese speakers}

Voicing assimilation before sonorants does seem to influence the production of epenthesis by Portuguese speakers. The total frequency of voicing assimilation and the rate of epenthesis of $/ \mathrm{sN}$ / and $/ \mathrm{sl} /$ clusters is summarized in Table 4 . As can be observed, participants voiced the $/ \mathrm{s} /$ in $55.60 \%$ of $/ \mathrm{sN} /$ clusters, and out of these, 56.83\% were pronounced with epenthesis. A much lower rate 
of epenthesis, $11.71 \%$, was obtained in the productions of clusters where the sibilant was not voiced. Still concerning the category of /sN/ clusters, the contrast between the production of epenthesis in voiced items and in voiceless items resulted in a very significant chisquare $(\mathrm{X} 2(1, \mathrm{~N}=250)=52.10, \mathrm{p}<.0001)$. Similar rates were obtained in the production of the $/ \mathrm{sl} /$ cluster. In this cluster, the sibilant was voiced in $59.35 \%$ of the items, and out of these, $53.42 \%$ were pronounced with epenthesis. Again, epenthesis production without the voicing of the sibilant was considerably lower, 12.0\%. The difference between the percentages obtained for epenthesis in voiced and voiceless $/ \mathrm{sl} /$ clusters also resulted in a very significant chi-square $(\mathrm{X} 2(1, \mathrm{~N}=123)=20.19, \mathrm{p}<.0001)$.

Table 4: Rates of epenthesis and voicing assimilation by Portuguese speakers

\begin{tabular}{lcc}
\hline \hline & /s/-nasal & /s/-liquid \\
\hline Number of $[+\mathrm{vd}]$ items & $139(55.60 \%)$ & $73(59.35 \%)$ \\
Number of epenthesis & 79 & 39 \\
Rate of epenthesis & $\mathbf{5 6 . 8 3 \%}$ & $\mathbf{5 3 . 4 2 \%}$ \\
Number of $[-\mathrm{vd}]$ items & $111(44.40 \%)$ & $50(40.65 \%)$ \\
Number of epenthesis & 13 & 06 \\
Rate of epenthesis & $\mathbf{1 1 . 7 1 \%}$ & $\mathbf{1 2 . 0 \%}$ \\
\hline \hline
\end{tabular}

\subsection{The influence of phonological environment in the production of epenthesis}

The results of this study partially corroborate those of Rebello (1997), in that epenthesis was more frequently produced after a word-final vowel than after a word-final consonant. However, whereas Rebello (1997) found the greatest frequency of epenthesis at the beginning of an utterance (the null context), in this study, silence was the context which yielded the lowest frequency of epenthesis production. Considering the whole group of Brazilian participants, Table 5 shows that epenthesis occurred more frequently 
after open syllables, $40.70 \%$, followed by closed syllables, 32.12\%, and by silence, $21.80 \%$. These figures resulted in a very significant chi-square $(\mathrm{X} 2(2, \mathrm{~N}=1,493)=34.98, \mathrm{p}<.0001)$. The results obtained with Argentinean participants, however, corroborate those of Carlisle (1991, 1992, 1997), since all the participants produced more epenthesis after a word-final consonant, 39.64\%, followed by a wordfinal vowel, $22.65 \%$, and then by silence, $16.88 \%$, which resulted in a significant chi-square $(\mathrm{X} 2(2, \mathrm{~N}=1,315)=60.48, \mathrm{p}<.0001)$.

Table 5 - Rates of epenthesis production by Portuguese and Spanish speakers in different environments

\begin{tabular}{|c|c|c|c|c|c|c|c|c|c|}
\hline \multirow{2}{*}{\multicolumn{2}{|c|}{ Participants \# prod. }} & \multirow[b]{2}{*}{ \# epen } & Null & \multicolumn{2}{|c|}{ Vowels } & \multirow{2}{*}{\multicolumn{2}{|c|}{ Consonants }} & \multirow{2}{*}{\multicolumn{2}{|c|}{ epen. \% epen }} \\
\hline & & & & & & & & & \\
\hline$\overline{\mathbf{B R}}$ & 344 & 75 & 21.80 & 570 & 232 & 40.70 & 579 & 186 & 32.12 \\
\hline 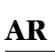 & 314 & 53 & 16.88 & 499 & 113 & 22.65 & 502 & 199 & 39.64 \\
\hline
\end{tabular}

\section{GENERAL DISCUSSION}

Results concerning the first hypothesis, that longer clusters would be more difficult to produce for Spanish spakers and shorter clusters for Portuguese speakers, reveal that both Portuguese and Spanish EFL speakers inserted an epenthetic vowel more frequently after tri-literal than after bi-literal clusters, confirming the predictions based on the $\mathrm{MDH}$, which claims that more marked structures are more frequently modified. The hypothesis for Spanish speakers was thus confirmed, but not for Portuguese speakers. This might be explained by the fact that in Rebello (1997) differences between shorter and longer clusters were extremely small, since her participants did not read the sentences fluently, given that they had a low level of English proficiency, which led them to produce epenthesis so frequently that the length of the clusters did not seem to be an influencing variable.

The second hypothesis claimed that clusters in violation of the SSC would be more frequently modified by Spanish speakers than 
clusters not in violation, and that clusters not in violation would be more frequently modified by the Portuguese speakers than clusters in violation. This hypothesis was confirmed for the Spanish speakers, corroborating the results found in previous studies by Carlisle (1991, 1992, 1997). The findings regarding the Portuguese speakers were inconclusive, which probably indicates the neutralization of opposing tendencies generated by the two different kinds of markedness: The first referring to the SSC, and the second referring to voicing.

The third hypothesis, which aimed at determining whether the phonological environment could be considered a variable constraint, predicted that Portuguese EFL speakers would produce a higher frequency of epenthesis after silence, followed by vowels and then by consonants, and that Spanish EFL speakers would insert an epenthetic vowel more frequently after word-final consonants, followed by vowels and then by silence. The results for the Spanish speakers followed the expected order. However, the results concerning the Portuguese speakers only partially confirm the hypothesis, since epenthesis was more frequently produced after vowels than after consonants, but silence was the context that produced the least rather than the most frequent epenthesis. This means that strength relations across the syllable affected the difficulty in producing English initial /sC(C)/ clusters, but differently for the two NL groups.

Therefore, some results found in this study are contrary to Rebello's (1997) findings. The production of Portuguese EFL speakers was analyzed in both studies; however, the difference in results might be explained by the participants' different levels of English proficiency. While in Rebello's investigation participants were learners attending English classes at the extracurricular course of a public Brazilian university, in the present study participants were learners attending the Letras course of the same university, which means that they were more proficient and already had some knowledge of English phonology, given that they are future EFL teachers. Thus, although the findings in this study are different from Rebello (1997), the results show that the production of /s/ clusters by Portuguese speakers is very different from that of Spanish speakers. 
Concerning the production of /s/ clusters by Spanish speakers, the results corroborate Carlisle's $(1991,1992,1997)$ findings, since (1) participants modified longer clusters more frequently than shorter cluster; (2) the insertion of an epenthetic vowel occurred more frequently before clusters in violation of the sonority hierarchy than before clusters not in violation; and (3) epenthesis occurred more frequently after vowels, followed by consonants, and then by silence. Considering, then, what was found by Carlisle and Rebello, the difference in results does not seem to have been caused by the differences in corpora. Differences in Spanish and Portuguese L1 show that native language interference and language universals can more accurately explain the dissimilarities.

\section{PEDAGOGICAL IMPLICATIONS}

The results of this and other studies on interlanguage phonology should convince materials writers to design pronunciation materials by presenting less marked TL structures before more marked structures. In this sense, bi-literal clusters should be presented before tri-literal clusters, clusters not in violation should be presented before clusters in violation, at least for Spanish speakers, and the /sl/ cluster should be presented before /sN/ clusters. Concerning phonological environment, this and other studies investigating Spanish EFL speakers found that $/ \mathrm{s} /$ clusters in vocalic environments cause less difficulty; thus they should be presented first to these learners. As regards Portuguese EFL speakers, this study and Rebello (1997) lead to the suggestion that consonantal and voiceless environments should be presented before vocalic and voiced environments.

Thus, research in interlanguage phonology would play an important role in helping both teachers and learners if the findings obtained in this interphonology research were taken into consideration in the development of language-specific series of English pronunciation manuals or textbooks that focus on the difficulties of each native language learner group. 
One limitation of this study has to do with the participants' level of proficiency, since they had already received phonological instruction regarding /s/ clusters, which is an aspect that influences the results of epenthesis production. Thus, an analysis encompassing EFL beginners and fluent speakers could reveal to what extent the variable proficiency plays a role in influencing the production of epenthesis before English initial /s/ clusters.

In addition to the inclusion of several proficiency levels and both elicited and natural speech, the difference between acquisition in natural settings and in the language classroom could also be analyzed. It is worth stressing that the studies by Carlisle were carried out in the United States, where learners were acquiring the language in a natural environment, unlike the learners in this study. However, a systematic study comparing the two environments would be useful, since it could contribute to a better understanding of how the learning process takes place in an informal versus a classroom environment.

\section{REFERENCES}

BARBETTA, P. A. Estatística aplicada às ciências sociais. Florianópolis: Editora da UFSC, 2001.

BRINTON, L. J. The structure of modern English: A linguistic introduction. Amsterdam/ Philadelphia: John Benjamins Publishing Company, 2000.

CARLISLE, R. S. The influence of environment on vowel epenthesis in Spanish/ English interphonology. Applied linguistics, v.1, n. 12, p. 76-95, 1991.

CARLISLE, R. S. Environment and markedness as interacting constraints on vowel epenthesis. In: LEATHER, J.; JAMES, A. (Org.). New Sounds 92. University of Amsterdam, p. 64-75, 1992.

CARLISLE, R. S. The modification of onsets in a markedness relationship: Testing the interlaguage structural conformity hypothesis. Language learning, v. 2, n. 47, p. 327-361, 1997.

ECKMAN, F. R. A functional-typological approach to second language acquisition theory. In: RITCHIE, W. C.; BHATIA, T. K. (Org.). Handbook of second language acquisition. San Diego: Academic Press, 1996. p. 195-211. 
HOOPER, J. Introduction to natural generative phonology. New York: Academic Press, 1976.

KATAMBA, F. An introduction to phonology. London/NewYork: Longman, 1989.

REBELLO, J. The acquisition of initial /s/ clusters by Brazilian EFL learners. Unpublished master's thesis. Universidade Federal de Santa Catarina, 1976.

SCHMIDT, R. The role of consciousness in second language learning. Applied Linguistics, n. 11, p. 129-158, 1990.

SEIDLHOFER, B. Pronunciation. In: CARTER, R.; NUNAN, D. (Org.). The Cambridge guide to teaching English to speakers of other languages. Cambridge: Cambridge University Press, 2001. p. 56-65.

WOODS, A.; FLETCHER, P.; HUGHES, A. Statistics in language studies. Cambridge, Cambridge University Press, 1986. 